\title{
The Connections between Above-Ground Biomass and Plant Diversity of Roadside Trees, Density and Diversity on Different Types of Roads in Karachi
}

\author{
Mir Muhammad Nizamani', Uzair Aslam Bhatti², Xia-Lan Cheng ${ }^{3}$, \\ Feroz Gul Nizamani ${ }^{4}$, Raza Ali Rind ${ }^{4}$, Aamir Ali Khokhar ${ }^{1}$, Chang-Wang Ma ${ }^{5,6}$, \\ Zeeshan Zeeshan ${ }^{7}$, Saraj Bahadur ${ }^{8}$, Dong-Mei Yang ${ }^{5,6 *}$ \\ ${ }^{1}$ Hainan Key Laboratory for Sustainable Utilization of Tropical Bioresources, College of Tropical Crops, \\ Hainan University, Haikou 570228, China \\ ${ }^{2}$ School of Geography, Nanjing Normal University \\ ${ }^{3}$ Lingnan Normal University, Guangdong, China, 520428 \\ ${ }^{4}$ Department of Plant Breeding and Genetics Faculty of Crop Production, \\ Sindh Agriculture University Tandojam, Pakistan \\ ${ }^{5}$ College of Horticulture, Hainan University, Haikou 570228, China \\ ${ }^{6}$ Key Laboratory for Quality Regulation of Tropical Horticultural Plants of Hainan Province, Hainan University, \\ Haikou 570228, China \\ ${ }^{7}$ Kymeta Corporation, Redmond Washington, USA \\ ${ }^{8}$ College of Forestry, Hainan University, Haikou 570228, China
}

Received: 29 July 2020

Accepted: 18 October 2020

\begin{abstract}
Although Karachi city is one of the world's fastest growing cities and considered one of the largest cities of the world, not much is known about its roadside trees. The roadside trees of different types of roads (e.g. Wide roads, Medium roads) in Karachi city of Sindhi, Pakistan were studied. Based on the field sample survey, tree species diversity of different types of roads were examined through different diversity indexes. Furthermore, the relationship between above ground biomass and biodiversity was studied by linear regression model. A total of 180 plots were surveyed, which were divided into three main types of roads. The most significant amount of tree biomass per unit area was found in Wide roads $4.27 \mathrm{~kg} / \mathrm{m}^{2}$, followed by medium roads. The least biomass per unit area was found in the narrow roads, where trees biomass per unit area was $2.44 \mathrm{~kg} / \mathrm{m}^{2}$. A single or a small number of species dominate in the observed area that decline the species diversity. A nonnative species Conocarpus erectus revealed dominance which was followed by Guaiacum officinale on all types
\end{abstract}

*e-mail:ydm5711@126.com 
of roads. Overall, 76 species (32 nonnatives and 44 natives) were noted, which were very disproportionately distributed in the roadside of the city.

Keywords: aboveground biomass of trees, types of roads, roadside trees, tree diversity, nonnative trees

\section{Introduction}

For coastal cities, roadside woody plants play an important role in ecosystem functions as well as in guarding them against natural catastrophes. Plants growing along the coastal area roadside can dissipate the wind and wave power and reduce the impact of tropical storms and associated storm surges, maintain coastline stability and integrity and so on. Plants embedded within the urban fabric can play a crucial role in mitigating and preparing cities for the challenges of climate change [1]. In recent years, the population and urban development areas of the world's coastal cities have grown at a fast pace. In the tropical region, most of the population growth is expected to be concentrated in coastal cities [2]. The diversity of urban woody plants is closely related to urban development, population growth and the urban functional units of the city. A rapid urban expansion could create novel ruderal habitats to complement the existing natural habitats, and these modified sites could be filled by native as well as exotic plants. Accidental or intentional introduction of alien species may contribute to an increase in plant diversity [3]. A coastal port city with plenty of exchanges in goods and people with other places around the world would generate many opportunities for exotic plants to arrive. Some of these newcomers could have the growth and reproductive capability to colonize or invade local ecosystems. The increase of plant diversity combined with other factors such as protected areas, defense against invasive alien species, sustainable agricultural methods and green infrastructure. The process of urbanization can preserve some pre-existing natural and semi-natural sites, and in addition, create a wide range of unique urban habitats to accommodate a diverse urban floristic assemblage [4].

The patterns and processes contributing to urban plant community invasion differ considerably from invasions in other plant communities. Where the density of an urban population is high, the area is typically also a hub for human-mediated commodity circulation. Transport links (e.g., airports, ports, roads, and rail networks) accelerate the introduction and spreading of exotic species across transmission routes and vectors [5]. Padayachee et al. [6] demonstrated that invasive plants were have being introduced to and shifted throughout cities via city-specific introduction routes and vectors. Cadotte et al. [7] reported that invasive species appear in cities with higher abundance and greater diversity due to elevated levels of interference and poorer contest. This work shows that invasive alien species have been more successful in urban areas than in the countryside or natural regions due to the fact that the novelty of habitat and ecological conditions has facilitated their propagation. Similarly, Kühn et al. [8] discovered that the relative impact of invasive and nonnative species to overall plant species richness rises with rural and urban gradients. Notably, they also discovered that invasive plants in urban and rural areas responded similarly to changes in ecological conditions. The high abundance of nonnative plant species in cities may be attributed to the existence of environmental and anthropogenic conditions which have a lesser impact on plant assemblages within cities versus rural areas.

The relationship between diversity and biomass could be characterized by diversity indicators such as Simpson [9] and Pielou [10]. Sun et al. [2] applied these indices to study other climate types in China, such as northern Mexico [11]. While studies on biomass and species diversity have been conducted in other locations, such as the tropical forests of Hainan Island, Southern China [12], Karachi City as a representative of Pakistan tropical coastal city, has not been assessed.

A forest ecosystem is a natural woodland unit that is composed of all biological components in the area functioning with the abiotic factors of the environment. One of the problems that need to be addressed in forest ecosystem services is to understand how and where above-ground biomass (AGB) and biodiversity align in space and time, and how management decisions may affect the complex relationships [13]. Although a few examinations have been done to explore such associations, the functional association between biodiversity and AGB in forest ecosystems still has controversy and is difficult to simplify [14].

To fill the knowledge gap mentioned above, we selected 180 areal sample units through a random sampling method in Karachi. The field survey measured the tree dimensions to calculate tree biomass. The study investigated two main research questions: (1) The patterns and differences in the diversity and density of tree communities of different types of road widths? (2) What is the role of native and nonnative tree species on the roadside? (3) How does tree biomass per unit area vary among different types of roads? (4) What is the relationship between tree biomass and species diversity index in different types of roads? (5) Which native species are under threat?

\section{Materials and Methods}

\section{Study Area}

Karachi is the biggest city in Pakistan as well as the $6^{\text {th }}$ biggest city in the world [15]. It is situated at $24^{\circ} 45^{\prime} \mathrm{N}$ 
to $25^{\circ} 37^{\prime} \mathrm{N}$ and $66^{\circ} 42^{\prime} \mathrm{E}$ to $67^{\circ} 34^{\prime} \mathrm{E}$ along the coastline of the Arabian Sea (Fig. 1). The city is elevated to 8 meters above the sea-level $[16,17]$. It has experienced prolonged warm summers and moderate winters. Summer is from March to October, and the average daily temperature is 25 degrees Celsius to 30 degrees Celsius. Wintertime continues from December to February, and the average daily temperature is $18^{\circ} \mathrm{C}$ to $20^{\circ} \mathrm{C}$. Summertime is wet and winter is dry. The city's average annual rainfall is low (175 mm), mostly during the rainy season from July to September. Presently, about twenty million people are living in the city, covering an area of 3,530.00 square kilometers [18]. Its yearly population increase rate is estimated to be $5 \%$. To examine the composition, density and taxonomic diversity of the roadside tree community.

\section{Data Collection}

The types of roads are divided into wide roads (24 $\mathrm{m}$ or larger), medium roads (12 $\mathrm{m}$ to $24 \mathrm{~m}$ wide) and narrow roads (width less than $12 \mathrm{~m}$ ) [19-21]. Karachi 's wide roads are the major roads bigger in size than other types of roads. Medium-wide roads are connecting roads between wide roads. Narrow roads are usually smaller than these two types. Urban management departments manage all types of roads and planting

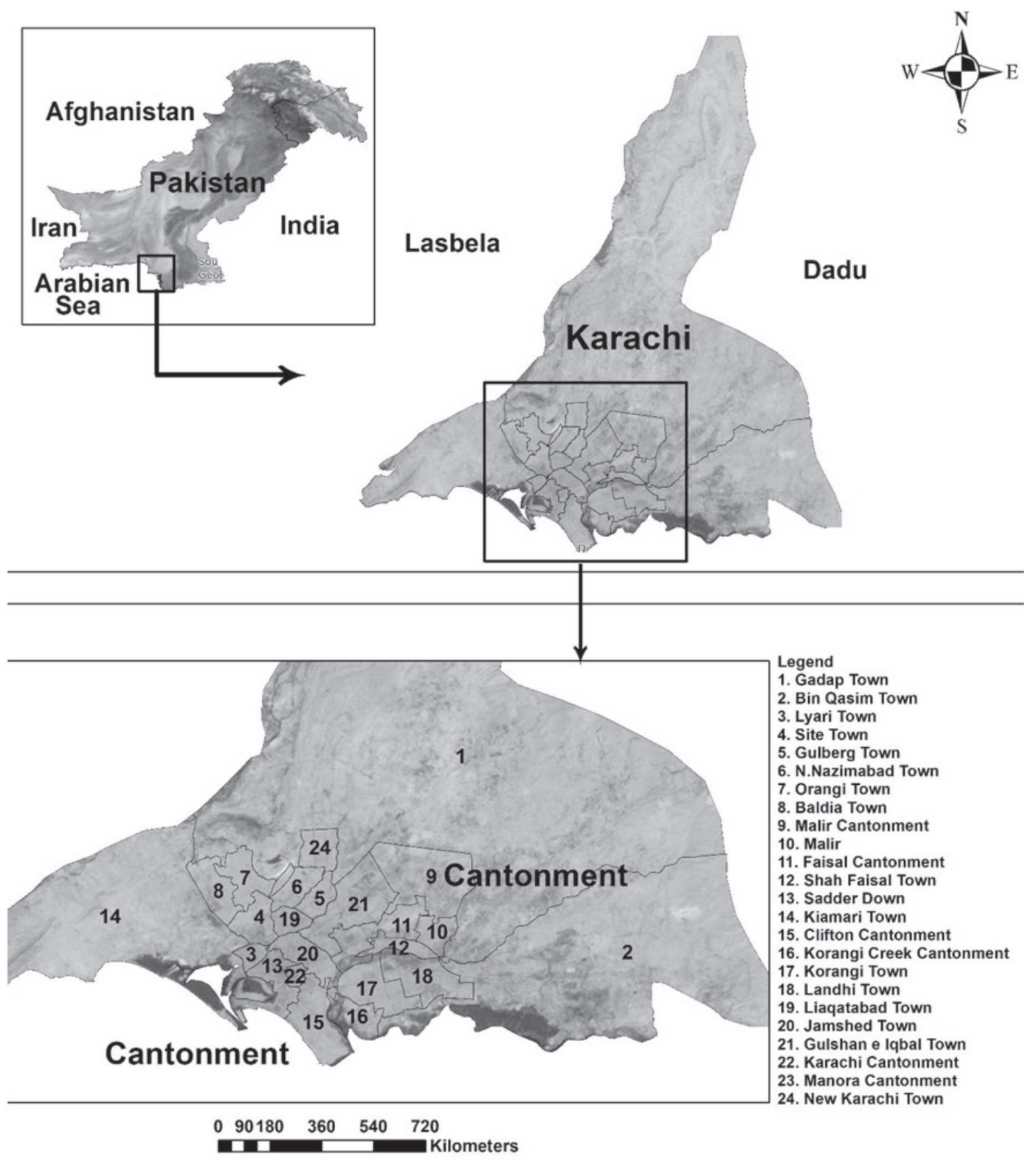

Fig. 1. Study site map with towns and cantonment area. 
trees. However, on narrow roads the sidewalks are close to homes, residents are also planting and caring trees.

The sampling plots were selected with the help of Google Earth [22]. The sampling plot of $1 \mathrm{~km} \times 100$ meters is randomly used on each road. The attribute lines on either side of the road are regarded as the width of each road. A total of 180 plots were measure on all types of roads, each road type has equal plots. The main data measured at the sampling point are the tree species name, number of trees, diameter $(\mathrm{cm})$, height $(\mathrm{cm})$ and crown width of each roadside tree.

\section{Data Analysis}

\section{Access of Species Diversity Data}

The plant species diversity index was used as the most basic and concise value to denote species diversity in the plant community, and the stability index was employed to determine the stability of the ecosystem [23]. We used Simpson and Pielou species diversity indices. The computational formulas are explained below.

1. Species richness $(\mathrm{S})$ : refers to the number of species of trees in each urban structural unit.

2. The Simpson Diversity Index (D): refers to the likelihood that the corresponding number of individuals derived from two successive samples of a community species that belong to the same species [9]:

$$
\mathrm{D}=1-\sum_{i=1}^{n} P i^{2} P_{i}^{2}=\frac{\mathrm{n}_{i}\left(n_{i}-1\right)}{\mathrm{N}(\mathrm{N}-1)}
$$

3. Pielou evenness index $(\mathrm{J})$ : refers to the distribution of the number of individuals in a community or environment [10].

$$
\mathrm{J}_{\mathrm{e}}{ }^{\prime}=\frac{H_{e}^{\prime}}{H_{\max }^{\prime}}
$$

Key points about each measured diversity index are presented in Table 1 .

We used $R$ language software to analyze the scatterplot analysis. We set each diversity index as an independent variable and aboveground tree biomass as the dependent variable and plotted the results in $x-y$ graphs (Fig. 5).

\section{Calculation of Above-Ground Tree Biomass}

Wang and $\mathrm{Xu}$ [24] summarized a large amount of data and used the model-fitting method to approximate and synthesize the following formula for the tree biomass of Haikou. We used it to calculate the aboveground tree biomass of the urban functional units:

$$
A G B=0.4 \pi\left(\frac{d b h}{2}\right)^{2} \times(\text { height }+300) \times(\text { wood density })
$$

AGB: Aboveground biomass of trees ( $\mathrm{g}$ )

$\mathrm{dbh}$ : breast diameter $(\mathrm{cm})$

Height: tree height $(\mathrm{cm})$

Wood density: wood density $(\mathrm{g} / \mathrm{cm} 3)$

The wood density of every species was derived from the TRY trait database [25].

\section{Results}

Most tree aboveground biomass per unit area was observed in Wide road, where the average tree aboveground biomass is $4.33 \mathrm{k} / \mathrm{m}^{2}$. The least tree biomass per unit area was estimated in narrow road

\begin{tabular}{|c|c|}
\hline Index name & Key points \\
\hline \multirow{4}{*}{$\begin{array}{l}\text { Species richness } \\
\quad(\mathrm{S})\end{array}$} & Simple and easy to calculate and therefore intuitively appealing. \\
\hline & $\begin{array}{c}\text { However, because it does not account for relative abundance, it is often not sensitive to environmental } \\
\text { disturbance. }\end{array}$ \\
\hline & Species richness as a measure on its own takes no account of the number of individuals of each species present. \\
\hline & $\begin{array}{c}\text { It gives as much weight to those species which have very few individuals as to those which have many } \\
\text { individuals. }\end{array}$ \\
\hline \multirow{3}{*}{$\begin{array}{c}\text { Simpson } \\
\text { Diversity Index } \\
\text { (D) }\end{array}$} & $\begin{array}{l}\text { Simpson Diversity Index (D) provide more information about community composition than simply species } \\
\text { richness they also take the relative abundances of different species into account. }\end{array}$ \\
\hline & Simpson Diversity Index (D) is a measure of diversity which takes into account both richness and evenness. \\
\hline & $\begin{array}{l}\text { Simpson Diversity Index (D)gives more weight to the more abundant species in a sample. The addition of rare } \\
\text { species to a sample causes only small changes in the value of D. }\end{array}$ \\
\hline \multirow{2}{*}{$\begin{array}{l}\text { Pielou evenness } \\
\quad \text { index }(\mathrm{J})\end{array}$} & $\begin{array}{l}\text { Pielou evenness index }(\mathrm{J}) \text { is a measure of the relative abundance of the different species making up the richness of } \\
\text { an area. }\end{array}$ \\
\hline & $\begin{array}{l}\text { Pielou evenness index }(\mathrm{J}) \text { mathematically it is defined as a measure of biodiversity which quantifies how equal the } \\
\text { community is numerically. }\end{array}$ \\
\hline
\end{tabular}
$3.20 \mathrm{~kg} / \mathrm{m}^{2}$. The second-lowest tree biomass per unit

Table 1. Measured diversity indexes with key points about each index. 


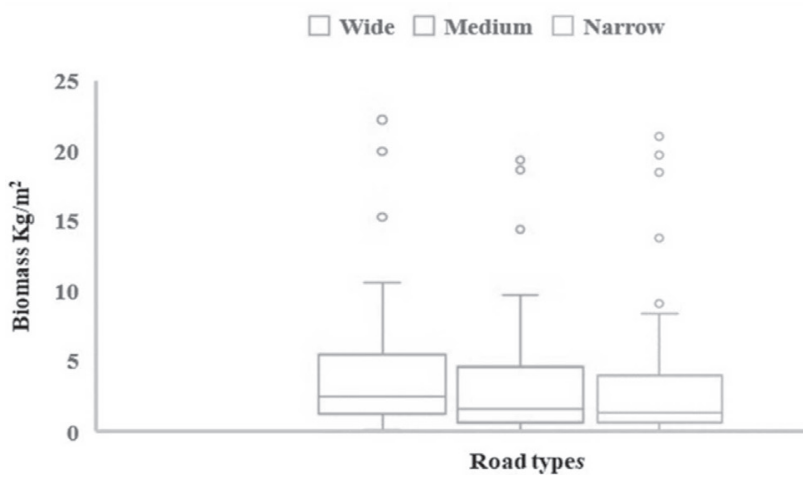

Fig. 2. Biomass per unit area of three road types of Karachi.

area measured in medium roads $3.50 \mathrm{~kg} / \mathrm{m}^{2}$ (Fig. 2, Table 2). In addition, there is a significant difference in the amount of above-ground biomass per unit area of roadside trees in the city. Overall lower species richness and diversity indexes were observed. Species richness ranges from 4.27-2.44. Simpson Diversity Index ranges from 0.62-0.32. Pielou's evenness index ranges from 0.31-0.26. In Wide road, maximum richness and diversity are observed followed by Medium and Narrow roads (Table 2).
Fig 3. shows that in nonnative trees Conocarpus erectus exhibited the highest number of trees (19589), which was followed by Guaiacum officinale (4318). Fig 4. shows that in native trees Azadirachta indica exhibited the highest number of trees (4074), which was followed by Ficus virens (1184). Overall, 76 species were observed 32 were nonnative and 44 were native. Nonnative species accounted for $73.65 \%$ and native species $26.35 \%$ of the tree community in all types of roads. In nonnative Conocarpus erectus accounted for $51.7 \%$ in the entire tree community, which was followed by Guaiacum officinale (22.04 \%) (Fig. 3). In native Azadirachta indica accounted for $10.77 \%$ in the entire tree community, which was followed by Ficus virens (3.13\%) (Fig. 4). The proportional representation distribution of nonnative species was greater than the native species in the observed area. Conocarpus erectus discovered solid dominance on all sorts of roads. Furthermore, fourteen native tree species are highly endangered (Table 3).

The aboveground tree biomass and diversity index of all samples of each type of road as shown in Fig. 5. We found that species richness and both diversity indexes were positively related to the biomass. The specie richness $\mathrm{R}^{2}$ value ranged from $0.218-0.106$.

Table 2. The mean of Species diversity, Simpson diversity index, Pielou evenness index and biomass in different Road types.

\begin{tabular}{|c|c|c|c|c|}
\hline Road types & Species diversity (S) & Simpson Diversity Index (D) & Pielou evenness index (J) & Biomass Kg/m² \\
\hline Wide & $4.27 \pm 2.12$ & $0.62 \pm 0.077$ & $0.31 \pm 0.55$ & $4.33 \pm 5.03$ \\
\hline Medium & $3.27 \pm 2.06$ & $0.52 \pm 0.077$ & $0.30 \pm 0.057$ & $3.50 \pm 4.64$ \\
\hline Narrow & $2.44 \pm 1.87$ & $0.32 \pm 076$ & $0.26 \pm 0.056$ & $3.20 \pm 4.73$ \\
\hline
\end{tabular}

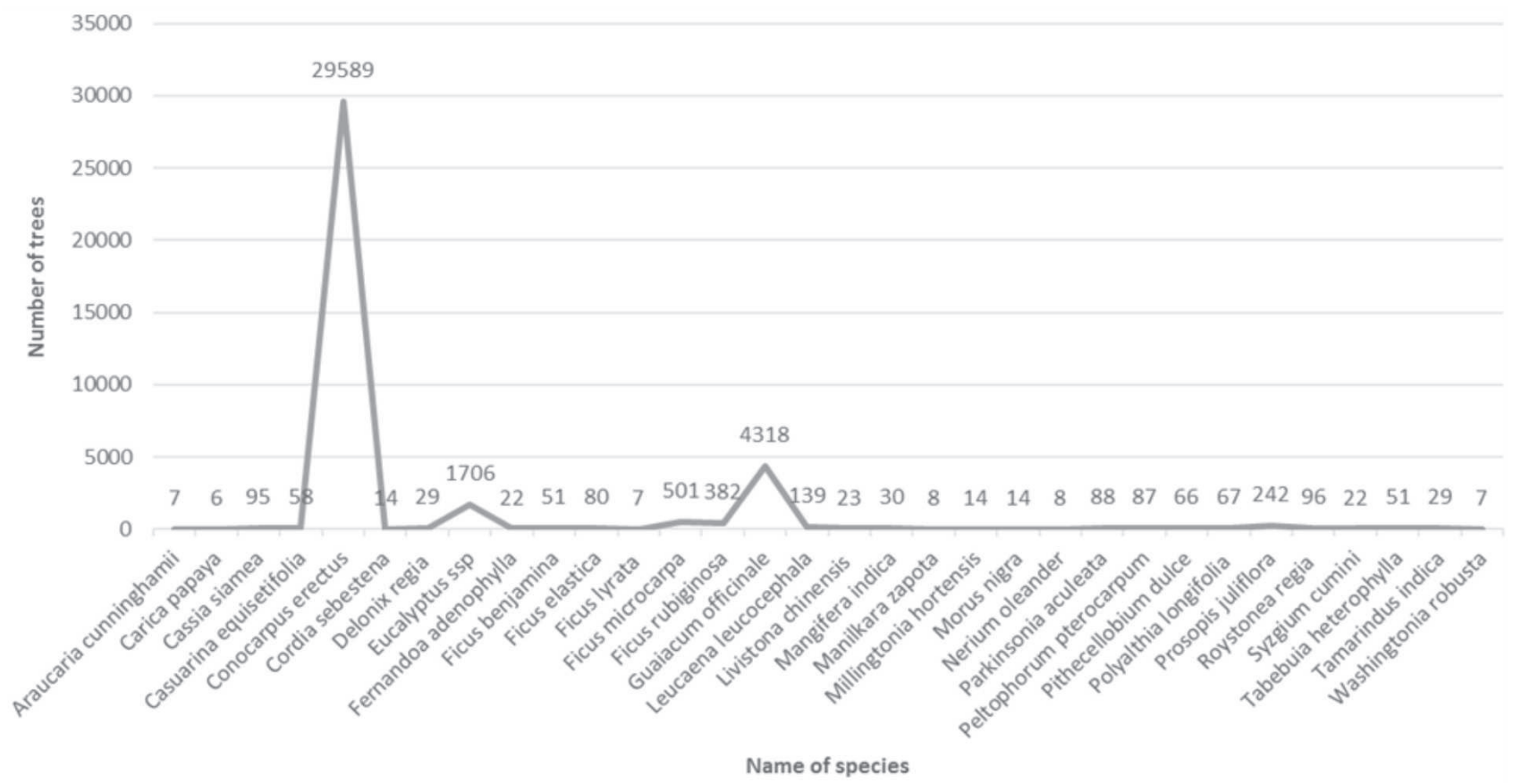

Fig. 3. List of nonnative species with the number of trees. 


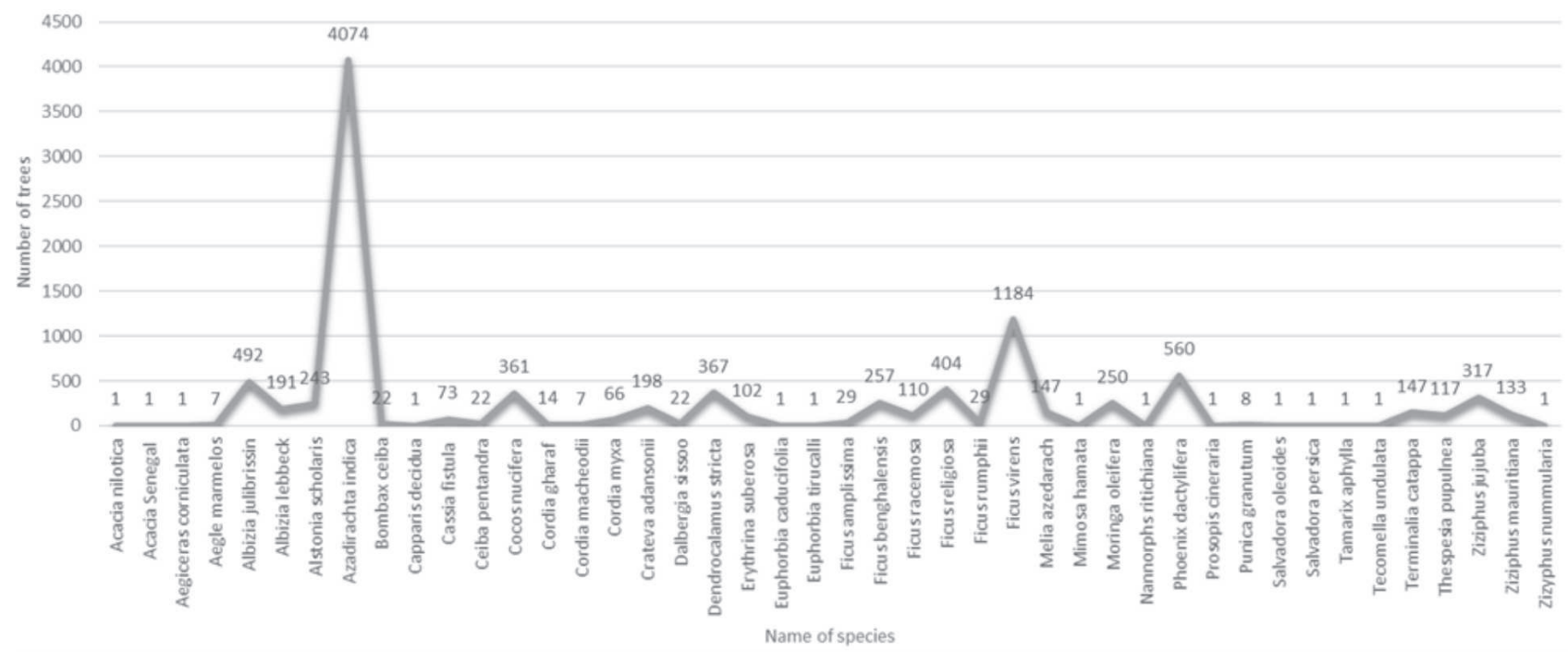

Fig. 4. List of native species with the number of trees.

The Simpson Diversity Index $\mathrm{R}^{2}$ value ranged from $0.175-0.095$. The Pielou evenness index $\mathrm{R}^{2}$ value ranged from 0.205-0.129 (Fig. 5).

\section{Discussion}

\section{Importance of Road Tree Populations}

Results revealed a strong dominance of Conocarpus erectus on the roadside of the city since which was followed by Guaiacum officinale (Table 2). Nonnative species accounted for $73.65 \%$ and native species $26.35 \%$

Table 3. List of threatened tree species of Karachi.

\begin{tabular}{|c|c|c|}
\hline Species name & Family & Number of trees \\
\hline Acacia nilotica & Mimosaceae & 1 \\
\hline Acacia Senegal & Mimosaceae & 1 \\
\hline Aegiceras corniculata & Primulaceae & 1 \\
\hline Capparis decidua & Capparidaceae & 1 \\
\hline Euphorbia caducifolia & Euphorbiaceae & 1 \\
\hline Euphorbia tirucalli & Euphorbiaceae & 1 \\
\hline Mimosa hamata & Mimosaceae & 1 \\
\hline Nannorphs ritichiana & Palmae & 1 \\
\hline Prosopis cineraria & Mimosaceae & 1 \\
\hline Salvadora oleoides & Salvadoraceae & 1 \\
\hline Salvadora persica & Salvadoraceae & 1 \\
\hline Tamarix aphylla & Tamaricaceae & 1 \\
\hline Tecomella undulata & Bignoniaceae & 1 \\
\hline Zizyphus nummularia & Rhamnaceae & 1 \\
\hline
\end{tabular}

of the tree community in all types of roads similar result reported by Shams et al., [21]. The structure of the roadside tree communities in Karachi can be compared with the structure of five American municipalities that showed significant advantages of the single species in their road tree community during the late 1980s [26]. In contrast, in all road types, the abundance of Conocarpus erectus is greater because the species has been widely cultivated in the past decade [27]. Therefore, the average diameter of the Conocarpus erectus (DBH) is lower than the native species of the tree community. During the study, upright large diameter standing trees were not common on urban roads. In addition, Conocarpus erectus is a medium (DBH) level species. On the other hand, the main tree species on American urban roads are high (DBH) level species documented on a large scale. Moreover, they are much older than Karachi.

In most official tree planting programs on the roadside of cities, single plantings were done, especially alien species [21, 27]. Civilian institutions usually cultivate and care for road trees. Because the sidewalks are close to houses, residents usually plant their trees along the roads. This increases the richness of other species and reduces monoculture. Due to native species, residents usually prefer to grow Azadirachta indica. Compared with a single species, multiple species are more stable to diseases, pests and infections [26, 28].

Planting a single species usually requires lower maintenance costs, but because of disease contamination or aging in the dominant species, it may bear heavy costs for its removal and replacement within a few years [26]. In numerous urban regions of the entire world, planting road trees alone has caused huge losses. For example, due to Dutch elm disease (Ophiostoma ulmi), millions of American elm trees (Ulmus americana) widely planted on North American roads have been eliminated. Increased taxonomic diversity in road tree communities reduces the risk of damage caused 


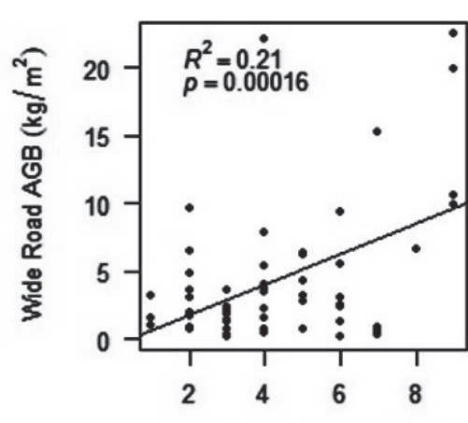

Species diversity index (S)
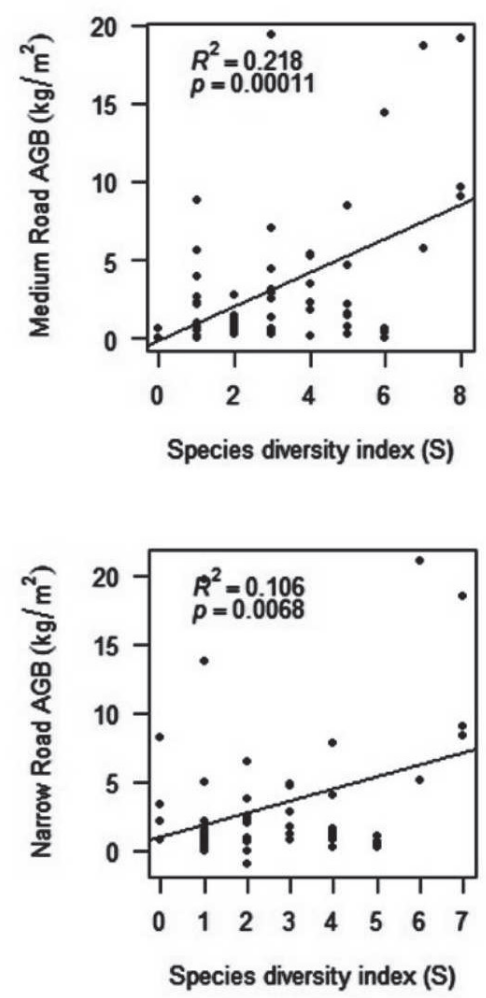

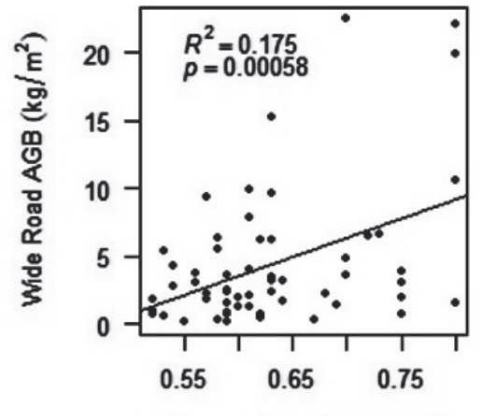

Simpson diversity index (D)
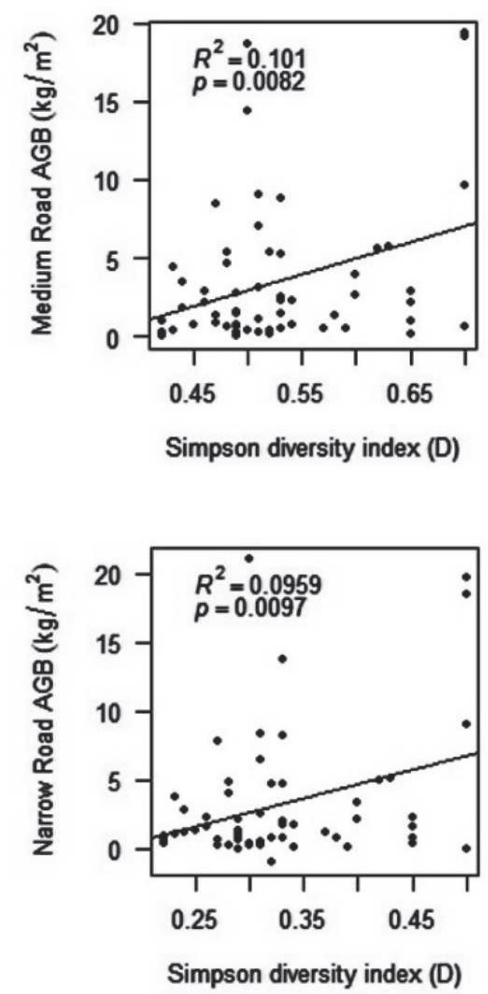

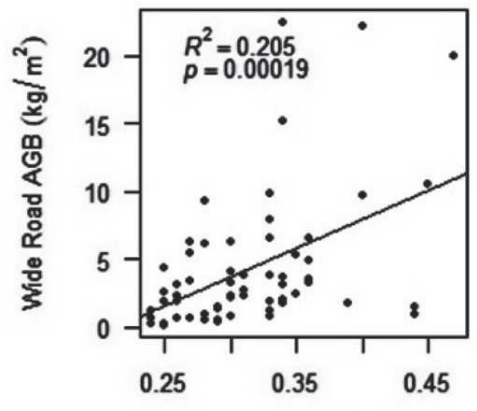

Pielou evenness index (Je)
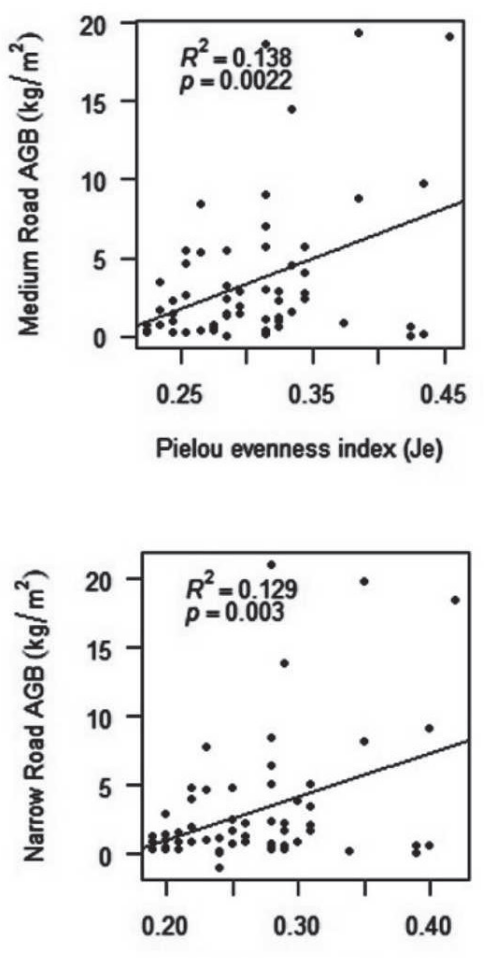

Pielou evenness index (Je)

Fig. 5. The relationship between tree aboveground biomass and plant diversity of roadside in Karachi.

by pests, diseases and insect pests and environmental changes [29-30].

Another area of concern is the widespread cultivation of exotic species throughout Karachi. Compared with native species, alien species are not suitable for cultivation in urban areas [31]. In addition, natural roadside trees have greater diversity and density than exotic species [32]. In contrast, compared to native species, the prevalence of mistletoe in alien species is much higher [33]. However, the alien species and native species provide the same ecological services for the stability of the metropolitan landscape [34]. In accordance with the study of Sjöman et al., [35], the exclusion of alien species in urban forests is usually unaffordable, mainly due to the limited supply of local species, which cannot meet the needs of ecosystem services in harsh urban landscapes. In adverse urban environments, many exotic species provide ecosystem services that are superior to native species [34]. Civilian institutions tend to grow alien species, mainly because of their rapid growth, which is mainly due to the influence of government agencies, thereby increasing the proportion in this coastal city. It is worth mentioning that the species diversity on the Karachi road was found to be lower than 22 cities in the United States [26] and cities in the Eastern Cape Province of South Africa [36].

\section{Variation of Above-Ground Tree Biomass in Urban Functional Units}

Our research shows that the Wide roads aboveground tree biomass per unit area far exceeds that of other urban functional units. Such a result indicates that the species abundance is high and/or that the number of trees per unit area in the area of the Wide roads is large. One reason for the variability in tree biomass in the Wide is related to the greening rate of the Wide roads. The trees 
used for natural products will probably be maintained through land-use changes. This positive trend was likewise seen in Shanghai [37]. Simmons et al. [38] discovered that natural product trees were retained on private land uses for financial and aesthetic purposes. Urban residents highlight the practical applications of urban greenspace that accommodate to the individuals [39]. Studies of trees further demonstrated the dominance of species with attractive and emblematic qualities [40].

\section{Relationship between Above-Ground Tree Biomass and Plant Diversity}

There is a substantial association between the aboveground biomass and plant diversity because when specie richness, Simpson index and Pielou index diversity indexes increase with increasing biomass. The current research focus is on the connection between species diversity and biomass. We wanted to explore the general model of biomass and species diversity as an extension of what we now know about biodiversity. Community diversity and the changes in biomass mainly depend on the growth environment and the adaptability of plants. The growth environments are reflected by the diverse characteristics of plants and their growth and development [41]. In addition, our study only studied the diversity of tree species, which may not be very consistent with the diversity of other taxa [42, 43]. Xue et al. [44] found that in the protection of high-carbon ecosystems, the diversity of tree species does not always reflect the diversity of shrubs and herbaceous species [45]. The focus of the present research was to study the correlation between species diversity and biomass. We wanted to explore the general model of biomass and species diversity as an extension of what we now know about biodiversity. According to our result, highly significant positive linear regression appeared between the species richness and above-ground biomass our results match with previous researchers like [46, 47]. While others have contradicting results with us to negative linear [48], unimodal [49], and non-significant [50-52].

\section{Conclusion}

The above-ground biomass and plant diversity because they have a simple linear relationship, when species richness, Simpson index and Pielou index diversity indexes increase, biomass also increases. The dominant position of a couple species in the city could be reduced by planting new different species in vast spaces, that can be found on all roadsides. In addition, other taxa should be introduced into urban tree communities with low species richness and diversity. Also, more threatened native species could be planted and all the essential amenities to invigorate diversity. However, invasive species that have not been transmitted by humans should not be planted in cities. To obtain sustainable and healthful city forests, trees with high-level taxonomy diversity must be evenly distributed on the roads [53]. The tree community must not be overshadowed by one or two species. The proportion of any single species in urban tree communities should not exceed more than 5\%. In Karachi single species dominate more than 50\%. Our study provides information that helps management for the conservation of biodiversity and ecosystem services.

\section{Acknowledgments}

This study is financially supported by 2019 High Level Talent Project of Basic and Applied Basic Research Program (Natural Sciences) of Hainan Province (project number: 2019RC167) and B-type Provincial Key Discipline Fundation of Hainan University (project number: 0902 Horticulture).

\section{Conflict of Interest}

The authors declare no conflict of interest.

\section{References}

1. ZAIATZ A.P.S.R., ZOLIN C.A., VENDRUSCULO L.G., LOPES T.R., PAULINO J. Agricultural land use and cover change in the Cerrado/Amazon ecotone: A case study of the upper Teles Pires River basin. Acta Amazon. 48 (2), 168, 2018.

2. ZHANG W., CHANG W.J., ZHU Z.C., HUI Z., Landscape ecological risk assessment of Chinese coastal cities based on land use change. Appl Geogr. 102174, 2020.

3. VICENTE J.R., VAZ A.S., QUEIROZ A.I., BUCHADAS A.R., GUISAN A., KUEFFER C., MARCHANTE E., MARCHANTE H., CABRAL J.A., NESPER M., BROENNIMANN O. Alien Plant Species: Environmental Risks in Agricultural and Agro-Forest Landscapes Under Climate Change. Clim. Change - Resil Agri \& Agrofor. 215, 2019.

4. WANG H.-F., QURESHI S., QURESHI B.A., QIU J.X., FRIEDMAN C.R., BREUSTE J., WANG X.-K. A multivariate analysis integrating ecological, socioeconomic and physical characteristics to investigate urban forest cover and plant diversity in Beijing, China. Ecol. Indic. 60, 921, 2016

5. WANG C., WU B., JIANG K., ZHOU J., DU D. Canada goldenrod invasion affect taxonomic and functional diversity of plant communities in heterogeneous landscapes in urban ecosystems in East China. Urban For Urban Gree. 38, 145, 2019.

6. PADAYACHEE A.L., IRLICH U.M., FAULKNER K.T., GAERTNER M., PROCHEŞ Ş., WILSON J.R.U., ROUGET M. How do invasive species travel to and through urban environments? Biol. Invasions. 19, 3557, 2017.

7. CADOTTE M.W., YASUI S.L.E., LIVINGSTONE S., MACIVOR J.S. Are urban systems beneficial, detrimental, 
or indifferent for biological invasion? Biol. Invasions. 19, 3489, 2017.

8. KÜHN I., WOLF J., SCHNEIDER A. Is there an urban effect in alien plant invasions? Biol. Invasions. 19, 3505, 2017.

9. SIMPSON E.H. Measurement of Diversity. Nature. 163, 688, 1949.

10. PIELOU E.C. The measurement of diversity in different types of biological collections. J. Theor. Biol. 13, 131. 1966.

11. MONARREZ-GONZALEZ J.C., GONZALEZ-ELIZONDO M.S., MARQUEZ-LINARES M.A., GUTIERREZYURRITA P.J., PEREZ-VERDIN G. Effect of forest management on tree diversity in temperate ecosystem forests in northern Mexico. Plos one. 15 (5), e0233292, 2020.

12. ALI A., LIN S.L., HE J.K., KONG F.M., YU J.H., JIANG H.S. Climate and soils determine aboveground biomass indirectly via species diversity and stand structural complexity in tropical forests. Forest Ecology and Management. 432, 823, 2019.

13. LAFORTEZZA R., CHEN J. The provision of ecosystem services in response to global change: evidence and applications. Environ Res. 147, 576, 2016.

14. JENNINGS M.D., WILLIAMS J.W., STROMBERG M.R. Diversity and productivity of plant communities across the Inland Northwest, USA. Oecologia, 143, 607, 2005.

15. BRINKHOFF T. Major agglomerations of the world. 2020. https://citypopulation.de/world/Agglomerations.html. (accessed on 28-05-2020).

16. KOTTEK M., GRIESER J., BECK C., RUDOLF B., RUBEL F. World Map of the Köppen-Geiger climate classification updated. Meteorol. Z. 15, 259, 2006.

17. Köppen-Geiger Climate Classification. Encyclopedia of Geography.

18. Karachi Metropolitan Corporation 2020. www.kmc.gos. $\mathrm{pk} /$ Contents.aspx?id=14. (accessed on 28-05-2020).

19. NAGENDRA H., GOPAL D. Street trees in Bangalore: Density, diversity, composition and distribution. Urban For Urban Gree. 9, 129, 2010.

20. DEB J.C., HALIM M.A., RAHMAN H.M.T., AL-AHMED R. Density, diversity, composition and distribution of street trees in Sylhet Metropolitan City of Bangladesh. Arboric. J. 35, 36, 2013.

21. SHAMS Z.I., SHAHID M., NADEEM Z., NAZ S., RAHEEL D., AFTAB D., FRAZ T.R., ROOMI M.S. Town socio-economic status and road width determine street tree density and diversity in Karachi, Pakistan. Urban For Urban Gree., 47, 126473, 2020.

22. https://earth.google.com (accessed on 28-05-2020).

23. CAI J.S., WANG X.M., TAN Z.C. The research on eco-restoration and follow-up industry development at Loess Plateau: taking mountain area at Southern Ningxia Province as an example. China Agric Press. 152, 2013.

24. WANG H.-F., XU M. Individual size variation reduces spatial variation in abundance of tree community assemblage, not of tree populations. Ecol. Evol, 7, 10815, 2017.

25. https://www.try-db.org/TryWeb/Home.php. (accessed on 28-05-2020).

26. MCPHERSON E.G., ROWNTREE R.A. Using Structural Measures to Compare Twenty-Two U.S. Street Tree Populations. Landsc. J. 8, 13, 1989.

27. SHAMS Z.I. Changes in diversity and composition of flora along a corridor of different land uses in Karachi over
20 years: Causes and implications. Urban For Urban Gree, 17, 71, 2016.

28. HE H., LIU L., MUNIR S., BASHIR N.H., WANG Y., YANG J., LI C. Crop diversity and pest management in sustainable agriculture. J. Integr. Agric. 18, 1945, 2019.

29. GWEDLA N., SHACKLETON C.M. Population size and development history determine street tree distribution and composition within and between Eastern Cape towns, South Africa. Urban For Urban Gree, 25, 11, 2017.

30. SJÖMAN H., ÖSTBERG J. Vulnerability of ten major Nordic cities to potential tree losses caused by longhorned beetles. Urban Ecosyst. 22, 385, 2019.

31. GARCIA-GARCIA M.J., SÁNCHEZ-MEDINA A., ALFONSO-CORZO E., GARCIA C.G. An index to identify suitable species in urban green areas. Urban For Urban Gree 16, 43, 2016.

32. NARANGO D.L., TALLAMY D.W., MARRA P.P. Nonnative plants reduce population growth of an insectivorous bird. Proc. Natl. Acad, 115 (45), 11549, 2018.

33. SHACKLETON C., Do indigenous street trees promote more biodiversity than alien ones? Evidence using mistletoes and birds in South Africa. Forests, 7, 134, 2016.

34. CHALKER-SCOTT L. Nonnative, noninvasive woody species can enhance urban landscape biodiversity. Arboric Urban For. 41 (4), 173, 2015.

35. SJÖMAN H., MORGENROTH, J., SJÖMAN J.D., SÆBØ A., KOWARIK I. Diversification of the urban forest - Can we afford to exclude exotic tree species? Urban For Urban Gree. 18, 237, 2016.

36. KURUNERI-CHITEPO C., SHACKLETON C.M. The distribution, abundance and composition of street trees in selected towns of the Eastern Cape, South Africa. Urban For Urban Gree. 10, 247, 2011.

37. WAN N.F., GU XJ., JI X.Y., JIANG J.X., WU J.H., LI B. Ecological engineering of ground cover vegetation enhances the diversity and stability of peach orchard canopy arthropod communities. Ecol. Eng. 70, 175, 2014.

38. SIMMONS B.A., ARCHIBALD C.L., WILSON K.A., DEAN A.J. Program Awareness, Social Capital, and Perceptions of Trees Influence Participation in Private Land Conservation Programs in Queensland, Australia. Environmental management, 1, 2020.

39. BUIJS A.E., MATTIJSSEN T.J., VAN DER JAGT A.P., AMBROSE-OJI B., ANDERSSON E., ELANDS B.H., STEEN MØLLER M. Active citizenship for urban green infrastructure: fostering the diversity and dynamics of citizen contributions through mosaic governance. Curr Opin Env Sust. 22, 1, 2016.

40. HUANG L., JIN C., ZHEN M., ZHOU L., QIAN S., JIM C.Y., CHEN B. Biogeographic and anthropogenic factors shaping the distribution and species assemblage of heritage trees in China. Urban For Urban Gree. 50, $126652,2020$.

41. ZHANG J.T., WANG C. Biodiversity and ecosystem functioning: exploring large-scale patterns in mainland China. Forrest. 5, 230, 2005.

42. LAWTON J.H., BIGNELL D.E., BOLTON B., BLOEMERS G.F., EGGLETON P., HAMMOND P.M., HODDA M., HOLT R.D., LARSEN T.B., MAWDSLEY N.A., STORK N.E., SRIVASTAVA D.S., WATT A.D. Biodiversity inventories, indicator taxa and effects of habitat modification in tropical forest. Nature. 391, 72, 1998.

43. SCHALL P., HEINRICHS S., AMMER C., AYASSE M., BOCH S., BUSCOT F., SIKORSKI J. Can multi-taxa diversity in European beech forest landscapes be increased 
by combining different management systems?. Journal of Applied Ecology. 2020.

44. XU W., LUO W., ZHANG C., ZHAO X., VON GADOW K., ZHANG Z. Biodiversity-ecosystem functioning relationships of overstorey versus understorey trees in an old-growth temperate forest. Annals of Forest Science.76 (3), 64, 2019.

45. ANJUM J., TIWARI A., SHEIKH M.A., SHARMA S. Floristic biodiversity and carbon stock of urban city with reference to educational institutes of gwalior: an approach of sustainability. Environment and Ecology, 38 (2), 183, 2020.

46. LI S., SU J., LANG X., LIU W., OU G. Positive relationship between species richness and aboveground biomass across forest strata in a primary Pinus kesiya forest. Sci. Rep. 1, 2227, 2018.

47. JOSHI R.K. Tree species diversity and biomass carbon assessment in undisturbed and disturbed tropical forests of Dibru-Saikhowa biosphere reserve in Assam North-East India. Vegetos. 1-22. 2020.

48. ZAMBRANO J., CORDEIRO N.J., GARZON-LOPEZ C., YEAGER L., FORTUNEL C., NDANGALASI H.J.,
BECKMAN N.G. Investigating the direct and indirect effects of forest fragmentation on plant functional diversity. PloS one. 15 (7), e0235210. 2020.

49. GEBREWAHID Y., MERESSA E. Tree species diversity and its relationship with carbon stock in the parkland agroforestry of Northern Ethiopia. Cogent Biology. 6 (1), $1728945,2020$.

50. BRANDL S.V. The relationship between forest productivity and site factors analyzed on the basis of forest inventory data (Doctoral dissertation, Technische Universität München). 2020.

51. VERMA P., SAGAR R., Responses of diversity, productivity, and stability to the nitrogen input in a tropical grassland. Ecological Applications, 30 (2), e02037, 2020.

52. TAO Y., ZHOU X.B., ZHANG J., YIN B.F., WU N., ZHANG Y.M. Humped relationship between herbaceous species richness and biomass reveals a potential for increasing productivity in a temperate desert in central Asia. Polish Journal of Ecology, 68 (1), 67, 2020.

53. MCPHERSON E.G., DOORN N.V., GOEDE J.D. Structure, function and value of street trees in California, U.S.A. Urban For Urban Gree.17, 104, 2016. 